\title{
Disease free survival (DFS) is a surrogate for Overall Survival (OS) in Localized Prostate Cancer (CaP)
}

Background: Advances in the treatment of localized CaP have lead to decreased recurrences and improved OS. The Intermediate Clinical Endpoints in CaP (ICECaP) Working Group is conducting an individual patient data (IPD) meta-analysis of possible surrogate endpoints for for localized CaP trials. We hypothesized that DFS is a surrogate for OS.

Methods: By June 2013, we systematically identified 102 eligible randomized trials (completed or ongoing) comparing treatments in localized CaP and collected IPD from trialists. DFS was defined from randomization (R) to the first evidence of clinical recurrence (loco-regional or distant) or death from any cause; or was censored at the date of last follow-up. OS was defined from $R$ to death from any cause. We evaluated the surrogacy of DFS with OS using a metaanalytic 2-stage validation model where 2 conditions must hold to claim DFS is a surrogate for OS (Buyse et al, 2000 \& 2011 - table). The secondary objective evaluated surrogacy of time to disease recurrence (TDR) with disease specific survival (DSS), defined analogously to DFS and OS but with non-CaP deaths censored.

Results: By January 2016, IPD from 16,999 men randomized in 20 mature trials were available for analysis. 32\% of the men were from prostatectomy trials, about $30 \%$ of the men had intermediate and 50\% high-risk disease and $86 \%$ were $<74$ yo. With median follow-up of 10.2 years, $32 \%(\mathrm{~N}=5,370)$ men had died and $30 \%$ of these deaths $(\mathrm{N}=1,592)$ were due to CaP.

\begin{tabular}{|c|c|c|c|}
\hline \multirow[t]{2}{*}{$\begin{array}{l}\text { Meta-analytic } 2 \text { - } \\
\text { stage validation } \\
\text { Model }\end{array}$} & \multicolumn{2}{|c|}{$\begin{array}{l}\text { Condition 1: } \\
\text { Correlation between the ICE } \\
\text { and true endpoint }\end{array}$} & \multirow{2}{*}{$\begin{array}{l}\text { Condition 2: } \\
\text { Correlation between } \\
\text { study specific } \\
\text { treatment effect on } \\
\text { endpoints } \\
\mathrm{R}^{2} \text { from weighted } \\
\text { linear regression of } \\
\text { treatment effects (log } \\
\text { HR - 95\% CI) }\end{array}$} \\
\hline & $\begin{array}{l}\mathrm{R}^{2} \text { from weighted } \\
\text { linear regression of } \mathrm{t}- \\
\text { year Kaplan Meier } \\
\text { estimates }(95 \% \mathrm{CI})\end{array}$ & $\begin{array}{l}\text { Plackett's } \\
\text { copula model } \\
\text { estimate of } \\
\text { Kendall Tau } \\
\text { correlation } \\
(95 \% \mathrm{CI})\end{array}$ & \\
\hline $\begin{array}{l}\text { DFS as a surrogate } \\
\text { for OS }\end{array}$ & $\begin{array}{l}10 y \text { OS vs } 5 y \text { DFS } \\
0.80(0.67,0.86) \\
8 y \text { OS vs } 5 y \text { DFS } \\
0.85(0.76,0.90)\end{array}$ & $0.85(0.85,0.86)$ & $0.80(0.60,0.87)$ \\
\hline $\begin{array}{l}\text { TDR as surrogate } \\
\text { for DSS }\end{array}$ & $\begin{array}{l}10 y \text { DSS vs } 5 y \text { TDR } \\
0.73(0.56,0.81) \\
8 y \text { DSS vs } 5 y \text { TDR } \\
0.79(0.67,0.85)\end{array}$ & $0.71(0.70,0.72)$ & $0.61(0.29,0.75)$ \\
\hline
\end{tabular}

Conclusion: DFS is a valid surrogate of OS and the correlation between TDR and DSS supports the notion that the correlation is driven by CaP events. 